\title{
The Mushroom at the End of the World On the Possibility of Life in Capitalist Ruins*
}

\author{
RESEÑADO POR PATRICIA ALVARADO PORTILLO**
}

The Mushroom at the End of the World (2015) es el último trabajo publicado por la antropóloga estadounidense de ascendencia china Anna L. Tsing. Ya famosa por obras como In the Realm of the Diamond Queen (1994) y Friction (2005), Tsing ahora propone un texto con un estilo relajado, en un inglés sencillo que hace muy amena su lectura. El libro forma parte de una investigación más amplia realizada por el Matsutake Worlds Research Group, donde participan académicos de diferentes latitudes del globo, y su publicación inaugura la divulgación de las reflexiones de este equipo proponiendo una nueva antropología "of always-in-process collaboration" (p. ix).

Los 20 capítulos de la obra articulados en un "open-ended assemblage" (p. viII) están distribuidos en cuatro grandes apartados que se intercalan con fotografías e ilustraciones sobre hongos, micorrizas y raíces, con la finalidad de presentar y transmitir mejor lo que la autora llama el "espíritu de su argumento”: mostrar cómo el hongo representa al mismo tiempo las consecuencias y alternativas al desastre generado por lo que ella caracteriza como un capitalismo patchy que sólo se revela en la interacción polifónica de las distintas formas de vida.

Cada capítulo comienza por lo general con una imagen y un poema, Haikou o fragmento literario que evoca al hongo estudiado: el cotizado matsutake, una especie silvestre que sólo se desarrolla y vive en bosques necesariamente intervenidos por la acción humana. El documento también contiene numerosas anécdotas que dan cuenta del universo social que se articula en torno al mencionado hongo, y cuyas voces se recogen para mostrar la complejidad de un proceso productivo atravesado por las historias, perspectivas y deseos de aquellos sujetos con los que la autora interactuó como parte de su investigación: estadounidenses, camboyanos o laosianos, khmer, mien o hmong, académicos, guardabosques, veteranos de guerra, refugiados, renegados o fugitivos de la ley por igual. La elaboración del libro tomó varios años debido al trabajo de campo desplegado durante las temporadas de cosecha del matsutake entre 2004 y 2011 en Estados Unidos, Japón, Canadá, China y Finlandia. Por ello, algunos capítulos fueron publicados o difundidos en otros espacios (revistas académicas, congresos) entre 2008 y 2013. Además de los países ya señalados, la autora realizó entrevistas en Dinamarca, Suecia y Turquía.

Por otro lado, la obra se complementa con el material de una página de internet, ${ }^{1}$ donde se pueden revisar fotografías y videos que dan testimonio de algunos segmentos del camino transitado por el matsutake. Este parasitio (Marcus, 2015) ilustra también la perspectiva multisituada que le permitió a Tsing seguir a la cosa para entender el proceso de su vida social y tejer la red virtuosa que la articula a otros procesos sociales en diferentes partes del mundo (véanse Wolf, 1987; Appadurai, 1991; Marcus, 1995; Mintz, 1996).

Al igual que en su libro anterior, en The Mushroom Tsing recurrió a la metáfora de la fricción para exponer cómo los contactos -heterogéneos y desiguales-, que son a la vez movimiento, interacción, ritmo, resistenciay aceleración, hacen que formas culturales diversas puedan llegar a nuevos arreglos culturales y de poder. Vuelve a trabajar bajo un complejo andamiaje de metáforas a través de las cuales ejemplifica procesos de resistencia y manejo de la perturbación. El hongo es la metáfora que ilustra el proceso de destrucción creativa y de sobrevivencia a la destrucción y la precariedad de las historias de personas que viven en los límites

\footnotetext{
* Anna L. Tsing, The Mushroom at the End of the World. On the Possibility of Life in Capitalist Ruins, Princeton University Press, Princeton, 2015, 331 pp.

**Estudiante de Antropología Social, Universidad Iberoamericana, Ciudad de México. Prolongación Paseo de la Reforma núm. 880, col. Lomas de Santa Fe, del. Álvaro Obregón, 01219, Ciudad de México <alvarado.paty@gmail.com>.

1 www.matsutakeworlds.org.
} 
del capitalismo o pericapitalismo, como le llama la autora.

El hongo es además el pretexto para hablar de vidas sin la promesa de la estabilidad y, aunque en el libro no se plantea una discusión profunda como tal, se abordan de manera crítica las ideas de modernización y progreso que se sostienen ampliamente bajo esta oferta. ¿Qué pasaría si aceptáramos que la inestabilidad, la precariedad y la contaminación son las premisas desde las cuales debemos imaginar nuestra subsistencia presente y futura? Las historias recopiladas por Tsing proponen distintas respuestas y formas de libertad instauradas desde el pericapitalismo. Ahora bien, cuando la autora habla de libertad se refiere a un modo de huir, evadir y eludir el capitalismo; por ejemplo, para los recolectores del matsutake, la cosecha no es un empleo; para los exiliados de guerra, el contacto con el bosque funciona como una terapia de sanación de sus experiencias de guerra y de la nostalgia de la migración, al tiempo que el dinero, producto de su colecta, les da acceso a bienes de consumo manufacturados. Desde ahí, desde esa libertad, se han desplegado estrategias para entrar y salir de los circuitos del capital, como la comercialización del matsutake, una de tantas tácticas de defensa y recuperación ante la marginalidad. La comercialización del hongo permite que los recolectores y los intermediarios minoristas y mayoristas lleven a cabo un proceso de acumulación de salvamento (salvage accumulation) (p. 55).

El matsutake es un actante multifacético. Comienza como un regalo de la tierra a los recolectores en algún bosque de Estados Unidos, Japón, China o Finlandia; se transforma en una mercancía global que es concentrada en Japón (país donde más se demanda); y vuelve a salir del circuito del capital cuando se compra para ser regalado. Rara vez el hongo es ingerido por aquellos que lo compran, por lo cual su valor va más allá de su precio. Tsing se apoya en Malinowski (1986) y su trabajo sobre el don para afirmar que la seta se convierte en una extensión de la persona, esta transición la saca del mercado de commodities y la inserta en un circuito donde lo que se mueven son dones.

Así pues, sería posible hablar de los diferentes avatares del matsutake, uno de los cuales se proyecta en la relación vendedores-compradores. Los primeros procuran un trato particular a los segundos cuidando y seleccionando los mejores ejemplares según las características del cliente y el acontecimiento para el que los necesiten. Éste es el primer don del matsutake identificado por la autoray sucede, dice, inclusive antes de que deje la esfera mercantil. La capacidad relacional de la seta es tal que el intercambio de dones a través suyo marca serios compromisos entre los implicados, circunstancia que alcanza a describir a la sociedad japonesa, pues, según sostiene uno de los informantes, "no se puede entender Japón sin conocer el matsutake" (p. 125; traducción propia). Con este camino dibujado a través del matsutake, Tsing nos invita a ver los saltos entre las formas capitalistas y no capitalistas articuladas desde los espacios periféricos, un proceso de constante traducción entre los diferentes avatares de las cosas que se producen dentro y fuera del sistema. Tsing ejemplifica uno de estos espacios a través de Open Ticket, un sitio en Oregón donde convergen recolectores y compradores minoristas. Ahí se lleva a cabo el performance de la competencia entre el regateo de unos y otros en medio de la clasificación de la calidad de los hongos y las expectativas de movimiento de los precios. Este teatro se realiza por una necesidad del drama, más que por el negocio mismo, dice la autora.

Ahora bien, aunque Tsing documenta a detalle las interacciones en el nivel micro, el lector no puede dejar de extrañar otra parte en la vida del hongo relacionada con las esferas macro, donde el matsutake se comporta como mercancía en tránsito, o su paso por los mercados mayores de subasta: ¿cómo es el proceso y quiénes son los acaparadores mayoristas, las empresas de carga o las comercializadoras que efectúan todo el movimiento terrestre, marítimo o aéreo del hongo a Japón?, ¿cuál es la tasa de ganancia que obtienen los trabajadores en función de su lugar en la cadena de distribución y comercialización?, ¿qué sucede con aquellos hongos que no logran "realizarse" como don? Éstas son algunas dudas que quedan en el aire y opacan la nitidez de la propuesta. En ese sentido, la idea de libertad que sostiene la autora nos hace reflexionar sobre qué tan real es la autonomía y la flexibilidad de los implicados y si sus percepciones pueden resultar suficientes para "escapar" del sistema de capital.

La historia que Tsing presenta está contada en gran parte desde la perspectiva de los hombres. Los recolectores, los vendedores, los compradores y aquellos que regalan el matsutake son preeminentemente figuras masculinas. Si bien la autora señala ciertos contactos con intelectuales feministas, no discute el papel diferencial de las mujeres, el cual considero un problema analítico que debe enfatizarse, pues, como otros trabajos han demostrado, el sistema sexo-género es determinante en la organización del sistema económico y social sea fuera -en el pericapitalismo- o 

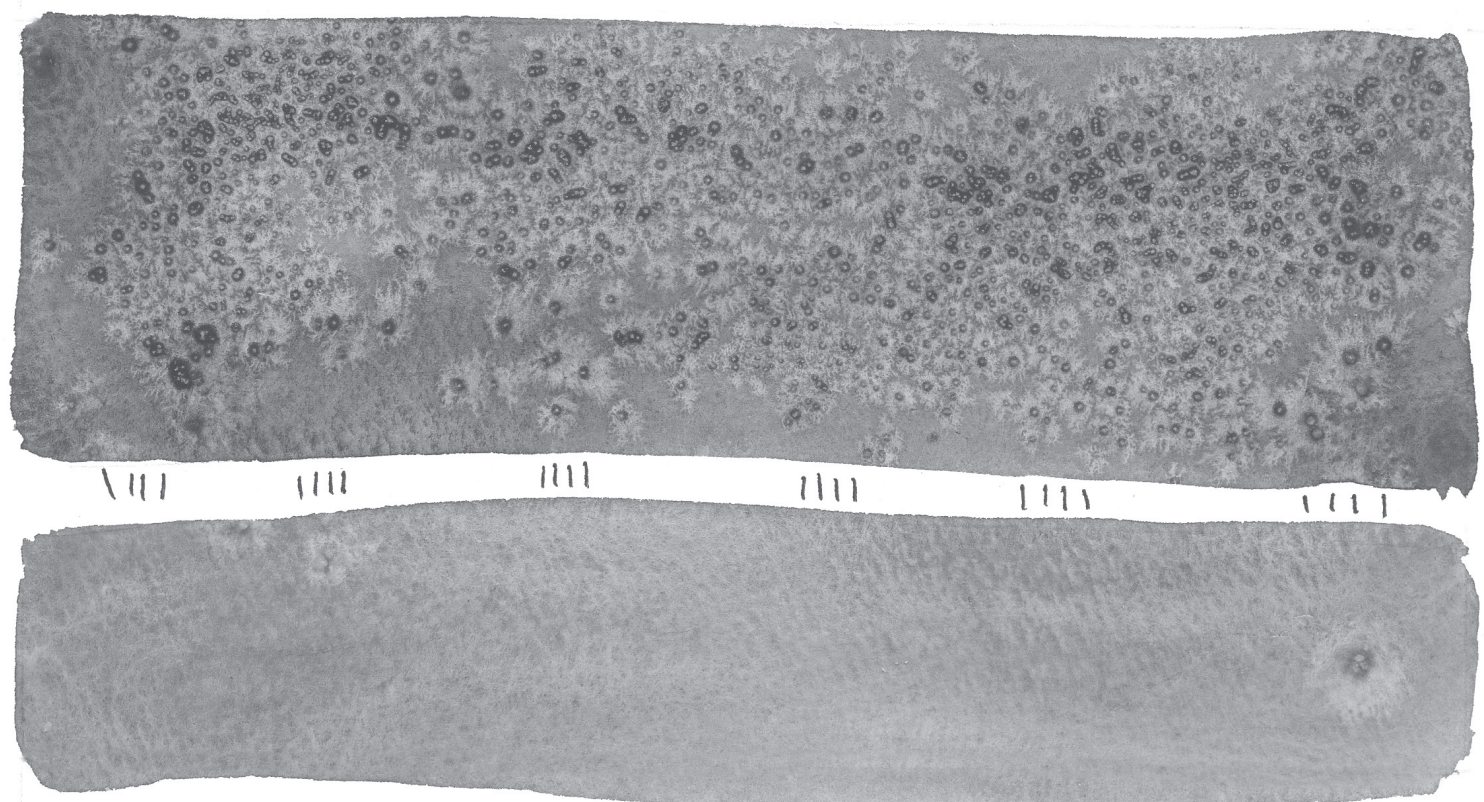

dentro del capitalismo (véanse Rubin, 1986, 2011; Strathern, 1988; Narotzky, 2004).

En contraparte, resulta interesante cómo la autora hace un recorrido histórico por las circunstancias que llevaron a mien, hmong y demás refugiados a Estados Unidos para entender y describir, estructuralmente, la conformación de la cadena global de suministro del matsutake, al tiempo que nos acerca a una parte importante de Asia que no siempre tenemos presente y lanza una mirada obligada al papel de México en ese proceso a través del programa Bracero. Este mecanismo permitió el movimiento de mano de obra mexicana para reemplazar a los japoneses que fueron consignados en los campamentos de reubicación abiertos en la Segunda Guerra Mundial.

Por último y como un objetivo paralelo, Tsing se propone demostrar otras metodologías para hacer etnografía y ciencia. Para ella, el libro es el resultado colectivo del grupo de investigación del que forma parte y desde donde piensa construir una academia-bosque superando el modelo plantación industrial con el que funciona actualmente. Tsing llegó preguntando en varios sitios por el matsutake y terminó discutiendo sobre hmong, mien, Laos, Tailandia y Camboya, la caza y la guerra, la libertad y el capital, la migración, el exilio y la esperanza a través de las posibilidades de sobrevivencia en un precario sistema de ruinas. El matsutake resultó la paradoja perfecta para mostrar todo esto y más.

\section{Fuentes}

Appadurai, ArJun

1991 Lavida social de las cosas, Consejo Nacional para la Cultura y las Artes, México, 406 pp.

MALINOWSKI, BRONISLAW

1986 LosargonautasdelPacífico occidental, Planeta-Agos-

Marcus, George E. tini, Barcelona, 505 pp.

1995 "Ethnography in/of the World System: The Emergence of Multi-sited Ethnography", en Annual Review of Anthropology, núm. 24, pp. 95-117.

Marcus, George E.

2015 "George Marcus Reflects on Ethnography and Innovation at UC Irvine", en CoLED <http: / coled. ucsd.edu/2015/09/04 / george-marcus-reflectson-ethnography-andinnovation-at-uc-irvine/> [ 16 de abril de 2017].
Mintz, Sidney D.

1996 Dulzura y poder. El lugar del azúcar en la historia moderna, Siglo xxi Editores, México, 200 pp.

NAROTZKy, SUSANA

2004 Antropología económica. Nuevas tendencias, Melusina, Barcelona, $351 \mathrm{pp}$.

Rubin, Gayle S.

1986 "El tráfico de mujeres: notas sobre la 'economía política' del sexo", en Nueva Antropología, año/vol. VIII, núm. 30, noviembre, pp. 95- 145 .

Rubin, Gayle S.

2011 Deviations: A Gayle Rubin Reader, Duke University Press, Durham, 484 pp.

Strathern, MARILYN

1988 The Gender of the Gift: Problems with Women and Problems with Society in Melanesia Studies in Melanesian Anthropology, University of California Press, Berkeley, 422 pp.

Tsing, Anna L.

1994 In the Realm of the Diamond Queen: Marginality in an Out-of-the-Way Place, Princeton University Press, Princeton, 220 pp.

Tsing, AnNa L.

2005 Friction: An Ethnography of Global Connection, Princeton University Press,

Wolf, ERIC R. Princeton, $337 \mathrm{pp}$.

1987 Europay lagente sin historia, Fondo de Cultura Económica, México, 609 pp. 